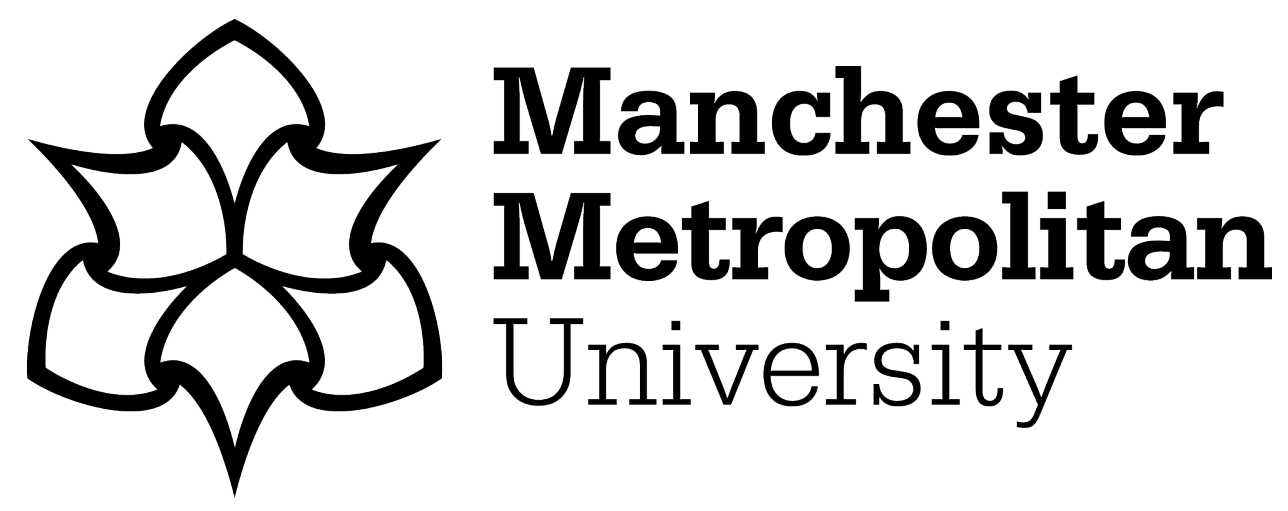

Prowse, Alicia ORCID logoORCID: https://orcid.org/0000-0002-1425-3274, Vargas, Valeria ORCID logoORCID: https://orcid.org/0000-0002-0008-0747 and Powell, Stephen ORCID logoORCID: https://orcid.org/0000-0003-39065867 (2020) Design considerations for personalised supported learning: implications for higher education. Journal of Further and Higher Education, 45 (4). pp. 497-510. ISSN 0013-1326

Downloaded from: https://e-space.mmu.ac.uk/626201/

Version: Accepted Version

Publisher: Taylor \& Francis (Routledge)

DOI: https://doi.org/10.1080/0309877X.2020.1789915

Please cite the published version 


\title{
Design considerations for personalised supported learning: implications for higher education
}

\author{
Alicia Prowse $^{\text {a** Valeria Ruiz Vargas }}{ }^{\mathrm{a}}$ and S. Powell ${ }^{\mathrm{a}}$ \\ ${ }^{a}$ University Teaching Academy, Manchester Metropolitan University, Manchester, UK \\ Alicia Prowse, University Teaching Academy, Manchester Metropolitan University, \\ Manchester, UK. a.prowse@mmu.ac.uk ORCID 0000-0002-1425-3274 \\ Valeria Ruiz Vargas, Faculty of Science and Engineering, Manchester Metropolitan University, \\ UK.v.vargas@mmu.ac.uk ORCID 0000-0002-0008-0747 \\ Stephen Powell, University Teaching Academy, Manchester Metropolitan University, \\ Manchester, UK. stephen.powell@mmu.ac.uk ORCID 0000-0003-3906-5867
}

*corresponding author

\section{Acknowledgements}

This work was supported by the Higher Education Funding Agency for England (HEFCE) under Interventions for Success Grant L09.

\section{Disclosure}

No potential conflicts of interest were reported by the authors.

\begin{abstract}
Attempts to personalise mass higher education systems have received increasing attention as universities compete to attract students. In the United Kingdom (UK), most higher education institutions have a system of personalised supported learning, usually called personal tutoring. Personal tutors are typically academic members of staff who support students to integrate into the university academic community. Institutions assume that a system of personal tutoring enables student satisfaction, progression and attainment - key performance indicators in competitive higher education landscapes. Personal tutors support their tutees in achieving their personal, academic or professional goals.

Systems of personal tutoring are often designed around what role the personal tutor should perform, rather than what purpose the role should serve. This paper uses thematic analysis of students' perceptions of personalised support for university learning, to elucidate improvements
\end{abstract}


to its' design and contributes to theorising effective personalised student support mechanisms. Insights from this analysis showed students could detect design that lacked sincerity, particularly in relation to adequate resourcing.

A central contradiction may therefore exist in resourcing personalised support within a mass higher education experience. A design tool using the dimensions to be considered in the approach to creating systems of personalised supported learning is presented and discussed.

Keywords: personal tutoring; academic advising; student support. 


\section{Background and rationale}

The rise in student numbers in the United Kingdom (UK) in the 1990s and early 2000s led to academics' concern about how to provide appropriate levels of support to all students (Grayson, Miller and Clarke, 1998; Walsh et al 2009). Personal tutoring in the UK is an activity intended to provide a personalised element to an experience that can feel impersonal within a mass higher education system (Hagenauer and Volet, 2014).

In some higher education systems, personal tutoring has been largely subsumed into a role that is performed by professional services staff rather than by academics, notably in the USA (Cate and Miller 2015) where academic advisers are recruited and trained for this function (Grey and Osborne, 2018). However, in the UK, personal tutoring is still seen as an important part of the university experience (for students) to be undertaken by academics. Indeed, for universities, it is sometimes seen as the answer to multiple and multi-faceted problems, such as student attrition and satisfaction (e.g. Roberts, 2018; Barbe, Kimble, Mellury and Rubenstein, 2018; MountfordZimdars et al 2017; Lochtie et al, 2018).

As UK universities increase their business-focus following more than a decade of marketisation of the sector, a professionalised and data driven approach to supporting students is becoming common (Kagan and Diamond, 2019). In this way, students are to be 'assessed' on entry to higher education for their vision and intent in relation to careers, their study skill development, and chances of engaging with university provision (e.g. Gray and Perkins, 2019). This is sometimes done on the basis of students being 'at risk' of not achieving the outcomes that the university has set for them - that of graduating with a good degree in a timely fashion; being satisfied with their experience; and entering a competitive job market at a graduate level where they will perform and provide their former institution with good 'graduate outcomes' measures (MacFarlane, 2015). However, this data-driven approach may help erode something vital in the informal contract between an academic and a student.

Alternatively, a professionalised and data driven approach can be seen as an inevitable consequence of a mass higher education system (Stephen, O'Connell and Hall, 2008). Thus while this debate continues in UK HE, the boundaries of the role come under close scrutiny. Should personal tutoring be chiefly pastoral, academic, or professional (Earwaker, 1992) or is there an ideal blend of these? Who should be providing personalised student experience elements? What expectations are generated in relation to personalised student experience, and how far are these expectations being met? 
Lochtie et al (2018) discuss UK higher education and the way that expectations of a personalised academic university experience have arisen. Expectations may be tracked back to ancient university teaching models (e.gin the UK, Oxford or Cambridge) of a personal system of apprenticeship, perhaps with discussion in comfy chairs, with added eccentricity and perhaps, paternalistic concern. While most UK universities are not able to resource this intensive model of personalised support, the idea of it, perhaps, persists.

Attempts to define the role of a personal tutor in UK universities have met with some resistance from academics (Ghenghesh, 2018) who may not see careers advice or pastoral care as within their remit (Tett, Cree, Mullins and Christie, 2017). However, attempts to rename the role 'personal academic tutoring' also meet with resistance because of a belief in the importance of the personal tutoring-student relationship (Hagenauer and Volet, 2014; Karpouza and Emvalotis, 2019). The centrality of this relationship leads to an inevitable mixing of academic and personal discussions that tend to occur within the remit of the role.

Work has already been undertaken on perception of what is, at least to some, a key function of an academic in the context of personal tutoring. For example, Yale (2019a) explored student perceptions of personal tutoring concluding that it is more damaging for a student to have a poor experience of personal tutoring than it is for them to have no experience, further making the case for working to create the best system that the university is able to offer. Yale's (2019b) more focused exploration of student experiences indicated that the first meeting a student has as part of the personal tutoring offering is key to their continued engagement. It is clear that perceptions of 'care' are vital to establishing a relationship of trust (Stephen et al., 2008). A definition of care is however, not easy to establish (Karpouza and Emvalotis, 2019) being very much a perception received, rather than a provision delivered.

Now, perhaps more than ever, it is important to see what students believe about the systems of personalised support that are offered to them and to try to ascertain what is of value to students. This is necessary so that universities can be clearer about their offer, and to understand how elements of positive and negative experiences of personal tutoring can be used to develop theory around this activity.

Personalised support such as personal tutoring has been under-researched compared to other aspects of learning and teaching scholarship (Braine and Parnell, 2011; Yale, 2019a), perhaps because of the inherent difficulties in seeking to define and create fertile conditions for academicstudent relationships that are not only functional but personalised and productive. Systems of personal tutoring tend to focus on what role the personal tutor should perform, rather than what 
purpose the role should serve. Consideration of students' perceptions of personalised support for learning could allow improvements to the design of systems of personal tutoring.

Asking students to talk about their experiences of personal tutoring shows that the activity is clearly useful to some students at some times (Lochtie et al, 2018); Yale 2019a). However, no evaluative or predictive models have emerged to suggest ways in which we can most successfully design systems for the activities which students themselves most value. This paper attempts to create a tool for design of personal tutoring systems could drive further theorising around the way we constitute both the role, the activities and the system in which we place these. Soft systems methodology (Checkland, 1989) is used to reach understandings of the main elements of systems of personal tutoring in a higher education institution in the UK to build a design tool for successful personal tutoring systems.

\section{Methods}

Finding out about a problematical situation is inimical to the methodology known as Soft Systems Methodology. Therefore, this was chosen as a way to explore the variously understood concept of 'personal tutoring', as the methodology is both structured and flexible.

Soft Systems Methodology (Checkland, 1989; Checkland and Poulter 2006) has been used in education settings as an action research-based model of change. The methodology considers the whole system (the institution, including its students and staff) as a 'learning system' that can explore, examine and problematise itself and generate its own solutions. In this research we learned about personal tutoring, alongside students and academic and support staff at all levels.

Checkland's (1989) work is usually seen as a form of action research, with a series of stages (Figure 1) defining a process of learning about the 'problematical situation' with 'action to improve' as a final outcome of an action learning cycle. Figure 1 identified the process, some stages (1, and 4-6) occur in the real world, whilst others (2,3) occur in a world of 'systems thinking' engaged in by various members of the learning system, and, principally, by the practitioners. 


\section{Soft Systems Methodology ( purpose and effectiveness)}

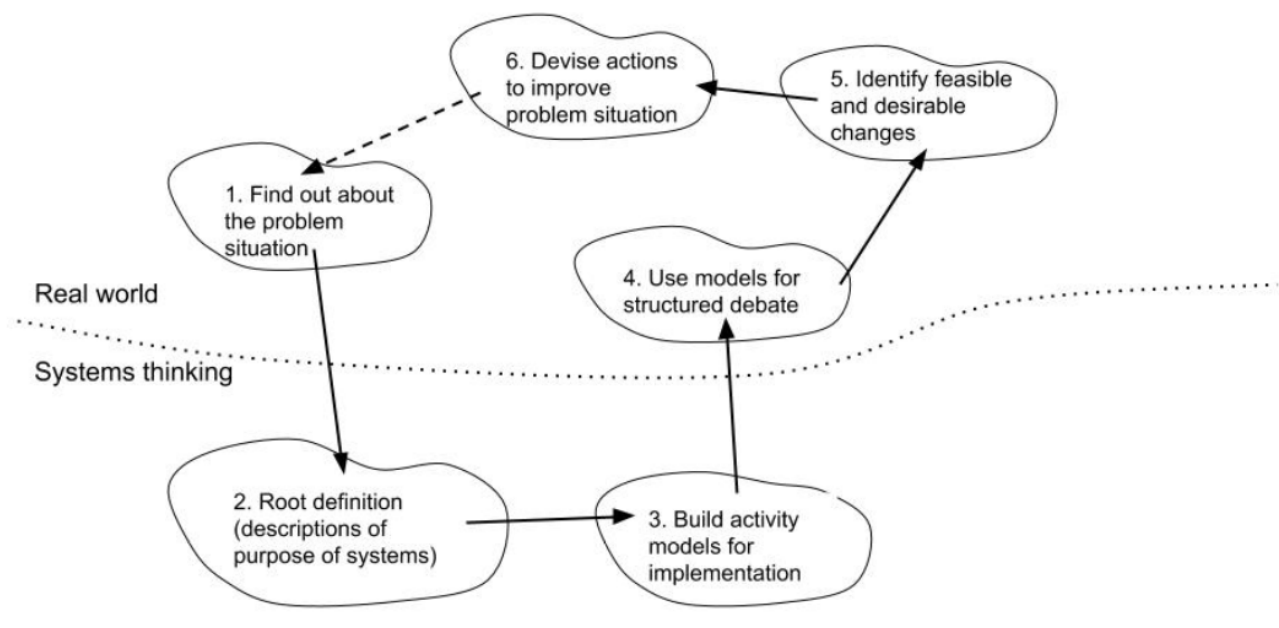

Soft Systems Methodology (Peter Checkland, 2006)

Figure 1. Overview of stages of Soft Systems Methodology (after Checkland and Poulter, 2006)

The stages of Soft System Methodology are described in detail in Checkland and Poulter (2006). The present account focuses mainly on Stages 1, 2 and 3. Stage 1 'Finding out about the problematical situation' is also often referred to as problem structuring - a systematic process that practitioners engage with in exploring the situation under investigation. This methodology was thus used to examine and describe the problematical situation around the activity known as personal tutoring at a large post 1992 university in the United Kingdom as part of a wider project.

\section{SSM Stage 1 Finding out: Student perceptions of personal tutoring}

We used two principal methods of finding out about students' experiences of personal tutoring. First, to explore a range of student experiences, students were engaged in informal conversations. These conversations occurred in each faculty's public space with a practitioner who was a recent graduate of the university. The practitioner offered refreshments to any students who approached, before seeking permission to record a brief chat on the topic of personal tutoring. Students tended to be in groups of between 2 and 4 . Where permission was explicitly given by the student(s), conversation was recorded. In total approximately 130 students contributed to these recorded conversations. Table 1 indicates the spread of courses and stage of study of the students. 
Table 1 Characteristics of students participating in the informal conversations. Year of study is undergraduate 1, 2 3, Foundation (F) or post graduate taught (PG). Percentages based on $\mathrm{N}=130$.

\begin{tabular}{|l|c|c|}
\hline Course & $\begin{array}{c}\text { \% of } \\
\text { total }\end{array}$ & Year of study \\
\hline Art Foundation & 3 & F \\
\hline Biological Science & 10 & $1,2,3$ \\
\hline Business & 9 & $1,2,3, \mathrm{PG}$ \\
\hline Chemistry & 6 & $1,2,3, \mathrm{PG}$ \\
\hline Combined studies & 2 & $\mathrm{~F}$ \\
\hline Environmental Biology & 6 & $1,2,3$ \\
\hline Early Years & 2 & 1 \\
\hline Education & 13 & $1,2,3, \mathrm{PG}$ \\
\hline Fashion & 1 & 1 \\
\hline Humanities & 3 & 2 \\
\hline History & 10 & $1,2,3$ \\
\hline Law & 3 & 1,3 \\
\hline PG Art and Design & 3 & 4 \\
\hline Maths & 3 & 2 \\
\hline Engineering & 3 & 2 \\
\hline Psychology & 6 & 2,3 \\
\hline Social care & 3 & 3 \\
\hline $\begin{array}{l}\text { Speech and Language } \\
\text { therapy }\end{array}$ & 4 & 1 \\
\hline Theatre & 3 & 3 \\
\hline Sport science & 9 & $2,3, \mathrm{PG}$ \\
\hline
\end{tabular}

Table 2 Characteristics of students participating in the written reflections.

\begin{tabular}{|l|l|l|}
\hline Student & $\begin{array}{l}\text { Year } \\
\text { of } \\
\text { Study }\end{array}$ & Course \\
\hline 1 & 1 & Physiotherapy \\
\hline 2 & 4 & Social Science \\
\hline 3 & 3 & Conservation Biology \\
\hline 4 & 2 & Law \\
\hline 5 & 3 & Psychology and Education \\
\hline 6 & 3 & English and Politics \\
\hline 7 & 3 & English Literature \\
\hline 8 & 2 & Law \\
\hline 9 & 2 & Biomedical Science \\
\hline 10 & 1 & History \\
\hline
\end{tabular}

Secondly, to gather some more in-depth and focussed accounts, ten students (Table 2) were recruited via the university's student worker scheme and paid to attend a briefing where they were tasked with writing two sides of A4 about their experiences of personal tutoring: 1) from their 
own viewpoint; and 2) from the point of view of a student they knew and with whom they would discuss their experience of personal tutoring. It was considered that the recruitment and briefing process could be biased in its construction towards students who have an interest in writing and in providing this kind of reflective narrative. Thus the second question was an attempt to balance this, whilst cognisant that this is a secondary account seen through the respondents' own filters. In completing this task, most students chose to ask a friend to contribute to 2) or paraphrased their view of a friend's experience.

\section{Data analysis}

The data from all student sources (informal interviews and written accounts) were pooled, and transcribed as necessary. A process of qualitative analysis followed Steps 1-6 of a data-driven thematic analysis (Attride-Stirling, 2001; Braun \& Clarke, 2006;) using this textual data. This analysis identified themes emerging directly from the data (Karunasena, Deng, \& Harasgama, 2015; Braun \& Clarke, 2006).

Step one in the process involved familiarising two researchers with the data, allowing for reading and re-reading of the texts. The two researchers then assigned codes to portions of transcribed text identifying a set of basic themes (Step 2). Conversations between the two researchers took place in order to consolidate the basic themes emerging (Step 3, Figure 2). A process of reviewing basic themes and further data reduction to compare, merge and discard overlapping or redundant themes, led to the creation of coherent organising themes (Step 4) which could then be defined and labelled (Step 5). The final step (6) identified essential global themes and assembles the whole in order to identify and refine the relationships between them.

The themes were then used to enable the building of a root definition (Stage 2 of the SSM) and to consider purposeful activity models (Stage 3, Figure 3). A root definition is essentially a purpose statement for the system which takes the form of 'do P, (i.e. what), by means of Q (i.e how) in order to achieve R (i.e. what)' (shared in the results section). Models of purposeful activity were then created based on the root definition, and used to reconsider the root definition in the classic iterative process of Stages 2 and 3. Stage 4 of the SSM aims to engage stakeholders in structured debate about the purposeful activity model. This paper thus provides a model (in SSM terminology) for structured debate. Taking this forward into the action to improve stage of SSM (Stage 5 and 6), elements were refined further and presented as a tool for designing a personal tutoring system. 


\section{Results}

\section{SSM Stage 1 Finding out}

This section reports on the results from the student conversations and written accounts.

Three main themes emerged from the student response, both from student conversations and students' written accounts justifying the pooling of the data for analysis. These were positive experiences, negative experiences, and suggestions for improvements. Three sub-themes featured in both positive and negative experience data: Affective Result, Structures and Communications (ie students' expressions of their feelings relating to the activity of personal tutoring) (Figure 2). In this section Affective Result, and the unique positive and negative themes are discussed. Discussion of the Structures and Communications themes are provided in section 4.

POSTIVE EXPERIENCE THEMES

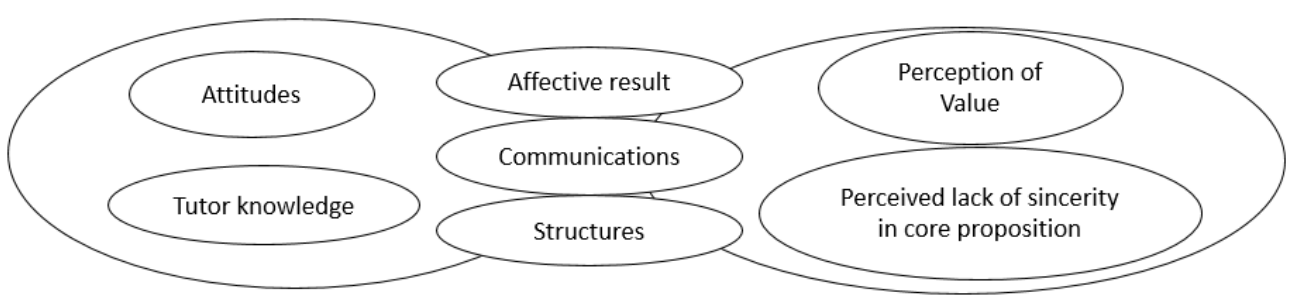

Figure 2. Positive and negative experiences of personal tutoring. Common themes in both positive and negative experiences are shown spanning both areas.

\section{Affective Result}

Where students had positive experiences, the affective result was expressed as a freedom from fear, pressure, or judgement. The students felt that their existence was not only tolerated, but welcomed.

We have mutual respect for each other... there when I needed...I don't feel pressured into doing something I am not comfortable with and I don't feel like they are too busy.

"... close guidance to give [tutees] emotional and educational support so they have three years of peaceful graduating"

Students felt "motivated" "confident" and "valued" where the personal tutoring relationship had been positive although this was often during the final year where dissertation tutors served as personal tutor: 
"She was very informative and maintained a positive and friendly atmosphere with personal and specific help"

Not feeling as if the tutor was too busy for them also chimed with feelings of being valued:

"They do not give the impression that they have better things they could be doing"

Students also expressed gratitude for the help that they did not perhaps envisage or that seemed beyond the duty of the personal tutoring:

"Had a foundation year and a year out. I wouldn't have done that if not for my personal tutor - he is amazing, he helped me out..."

Where students had negative experiences, the opposite was true with students feeling fearful of judgement, under pressure, or a 'nuisance'. Additionally there were feelings that related to the students' expectations of the role, that were not met. Students thus described feeling 'frustrated' 'disappointed' or not comfortable to 'open up'. Additionally, where there was a perceived lack of tutor interest, or lack of personal connection the personal tutoring activity could be seen as an inconvenience or chore.

In both the positive and negative experience data, students perceived that they had some control over their own input to the activity, and that this might impact the resulting quality of relationship:

"You have to choose to go rather than them coming to get you... They don't chase me... we have 5 [meetings] a year. I've had none. I would never just say, 'I'm going to book a tutorial... I don't take advantage of it."

\section{Structures and Communications}

These two major themes appeared in both positive and negative perceptions of personal tutoring activity although negative perceptions tended to focus on these aspects. Issues around timetabling, numbers of meetings, communication between students and staff, staff availability and staffing stability were common. The latter was particularly important for students seeking some continuity in their personal tutoring.

There were mixed reactions to the idea of group tutorials, with some students seeing this structure as less intimidating (a positive thing for shy or reserved students).

"Should always be 1-on-1 because speaking in front of a group can be inhibiting..."

Some students talked about the intensity of a scheduled 1:1 meeting being a reason for not attending, especially once they had missed one:

"I feel like I don't want to go to them as I am going to get told off."

However, others saw group meetings as much less personalised and wanted the personal tutoring space to be one that was explicitly for them as an individual where they could be challenged:

"More one-on-one contact, not group tutorials...more interactive 1 on 1 and to be challenged more..." 
One unexpected finding was a view about location of meetings, which revealed a strong preference for less formal, more relaxed interactions happening in, for example, coffee areas:

"I would rather go as a group, or come somewhere like here \{cafe\}..."

"There is an idea of what you're meant to talk about...[it would be] good if you could talk about other things, like workload and things."

"Don't have any say about where and when."

The lack of communications around the purpose of meetings was striking, suggesting either that communication is not occurring effectively or, perhaps, that the purpose of meetings is not clear even to personal tutors. In the positive data, personalisation, convenience and informed, organised communications, formal or informal, were appreciated.

\section{Attitudes and Tutor Knowledge}

Two themes related only to positive experiences of personal tutoring, Attitudes and Tutor Knowledge. These together with the positive Affective Result emphasised the importance of the relationship between tutor and student.

Attitudes related to both tutors and students taking their responsibility seriously, the perception that tutors treated students as individuals, and the possibility of the development of mutual respect.

Tutor knowledge (of the students) was a theme that was also strongly expressed, with a number of students noting the importance of a personal tutor's good knowledge of employability and contacts, and the value of "a mature person's advice". However, when a tutor knew the student as an individual, and had shown some interest or care that the student perceived as genuine, this was very much valued.

"There are tutors who know me for me...they could write a whole book chapter on me if they were asked to"

The centrality of a caring relationship was clearly and repeatedly evidenced. This finding is well known (e.g. Stuart, Willocks and Browning, 2019; Tett et al, 2017; Stephen et al 2008;). However, the perception of whether this care was genuine, was also clearly evidenced in the data (see next section).

Two themes identified in the negative experience data: Perceived sincerity of personal tutoring proposition and Perceived value of personal tutoring activity and the negative affect of these are explored further below.

\section{Perceived lack of sincerity of the personal tutoring proposition}

Students saw some negative experiences as evidence that the personal tutoring offer to care for, or help students on their own terms, was not genuine, but rather that the system was designed to 
suit the institution. This theme emerged from students who picked up on mixed messages about the value of the activity of personal tutoring as provided by the institution. Students could see that, in some instances, neither staff nor students valued what was on offer.

“...sometimes they don't provide enough tutors and sometimes they don't know the answer. We don't have regular sessions, if you want one you can have one. For them it is only mandatory to see us once a year."

"Feels a bit impersonal..."

"Somebody to go to with questions or for advice, although the word 'personal' has not been appropriate in my experience - it's always group tutorials or a different person." "...my tutor seemed very disinterested and like he was waiting for the meeting to end."

"Depends how good the relationship with the tutor is. In some cases it can be a negotiated process but often it's not."

"[the tutor] could have shown more interest to get to know me as a person...this is probably a consequence of her having so many students to deal with..."

This may suggest that the personal tutoring offer is poorly defined, or the way it is communicated is poorly articulated and some students noted this:

Honestly, I am not sure [what the purpose is] ...There's no need to have a day where you meet up and go and talk to them unless that is just a way for the uni to check up on you. I personally don't think there is any need for these group meetings at all.

\section{Perceived value of personal tutoring activity}

Looking at the overall picture of negatively perceived tutoring experiences, reasons for nonattendance were evident. For example, if there are structures in place (e.g. a number of 'compulsory' personal tutoring meetings in the year) that as a student you have no agenda for; whose purpose is poorly communicated; and in which neither staff nor students seem to be invested, then why attend?

"Students simply do not have time to attend sessions that aren't as important as actual lessons."

Some students clearly did not see personal tutoring as a high priority amidst the competing demands on their time:

“...students need more incentives to attend as a lot of them work and in some cases have several other commitments"

However, non-engagement with personal tutoring was also seen by students as something more to do with students than necessarily a reflection of the quality of the tutoring on offer. It was observed by students, that some "great tutors" only had two students turn up to a group session. 
Students also had many ideas and suggestions about how the personal tutoring experience could be improved. These were categorised as:

Greater personalisation of the system so it is more convenient to the whole of a student's life/timetable and related to this, allowing students to choose whether, where, when and how interactions with personal tutors occur.

Providing more communication about the purpose of personal tutoring, beyond a box ticking procedure.

Providing more meaningful interaction, including a genuine attempt to get to know about a student as an individual -perhaps requiring preparation for sessions.

Analysis of the positive and negative experiences themes as well as inclusion of student suggestions for improvements allowed use of stages 2 and 3 of the SSM as described below.

\section{SSM Stages 2 and 3}

The themes emerging fed into the development and refinement of a root definition with input from a range of stakeholders. The resulting statement of purpose of the system was to:

[do P]Facilitate students' personal development and academic progress, achievement, career readiness, aspirations and transitions into and out of university education over time, [by means of $Q]$ by encouraging the formation of purposeful relationships (e.g coaching, mentoring) with clear boundaries, between students and academic staff, [in order to archive R] to help students to navigate their own pathways towards autonomy and success.

The creation of models of purposeful activity to show how these might achieve the purpose (an example is shown in Figure 3) involved consolidating the data further focussed on those elements that the practitioners felt emerged most strongly as guides for design of personal tutoring systems. 


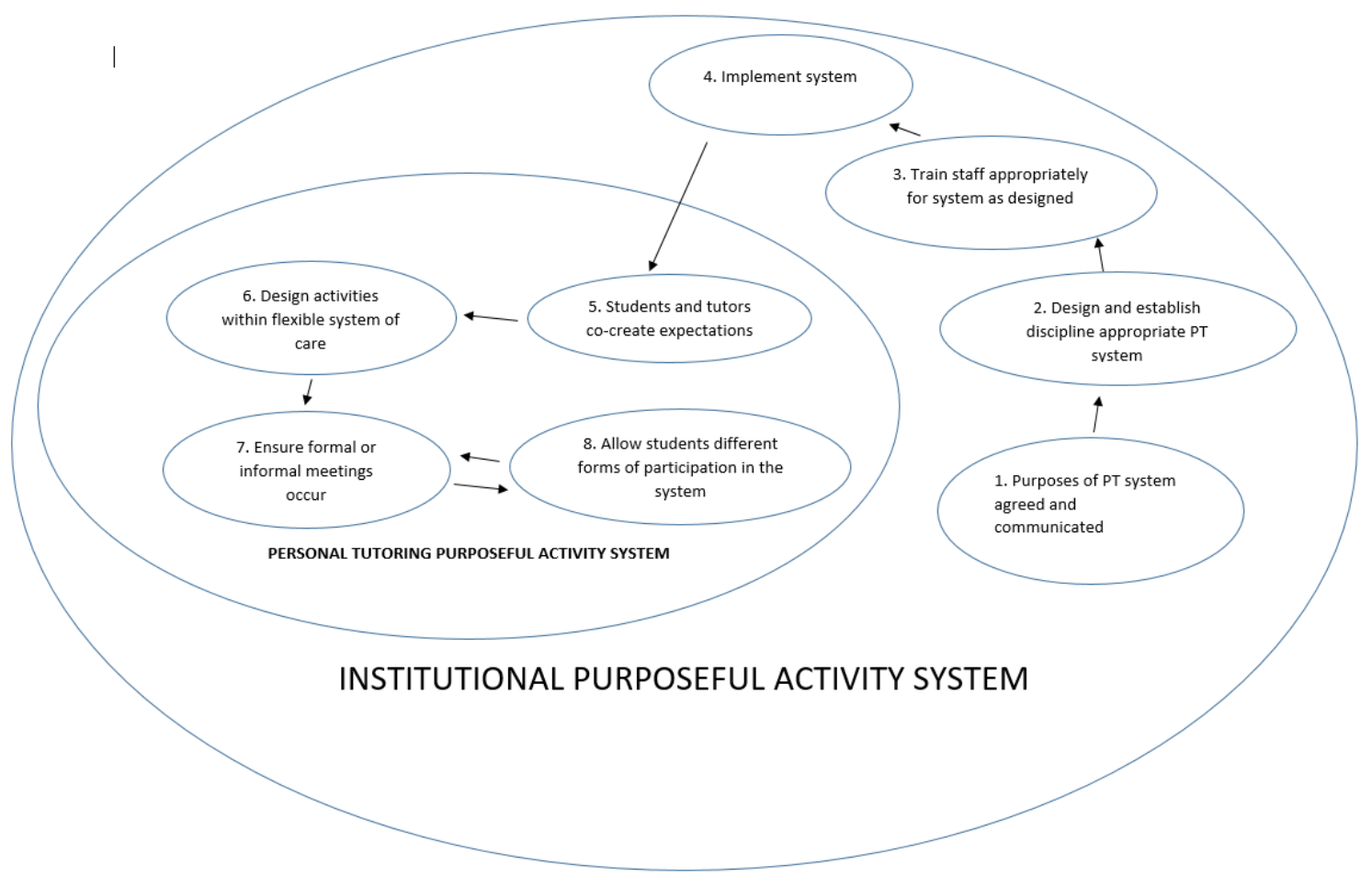

Figure 3. Example of an activity model to achieve the purpose of personal tutoring (Stage 3 of the SSM)

These elements were then used to create dimensions characterising four quadrants which encapsulated design considerations that could enable design of a system of personal tutoring able to successfully achieve its purpose or which could be used to evaluate existing systems and help diagnose issues. The composite dimensions were created from related themes in the positive and negative experience data (e.g. perception of sincerity and perception of value). This allowed further reduction of the data to build a simple tool to aid design of systems of personal tutoring activity. Two dimensions were thus created: 1) a dimension that describes perceived sincerity (and therefore) value of the personal tutoring proposition as these are closely related and; 2) effective communication of purpose and structures as these items were closely linked in both the positive and negative experience data.

\section{Design considerations for a successful personalised support scheme}

The positive experience data described communications and structures that worked for the students, and a congruence between levels of authentic engagement of staff in the act of care and the perceived role of the personal tutoring. This accords with previous empirical work on student perceptions of personal tutoring (Yale, 2019a; Stuart, Willocks and Browning, 2019) which showed that having a negative experience of personal tutoring is worse than having none. The 
negative experience data surfaced strong feelings in relation to the perceived utility of the activity and the sincerity of the offering of personalised support.

Reduction of the data resulted in a two dimensional explanation of the way in which a personal tutoring system might work using these dimensions as design considerations (Figure 4). Four quadrants are defined: CARE; HEROES; DISENGAGEMENT / AUTONOMY; and NO ONE CARES.

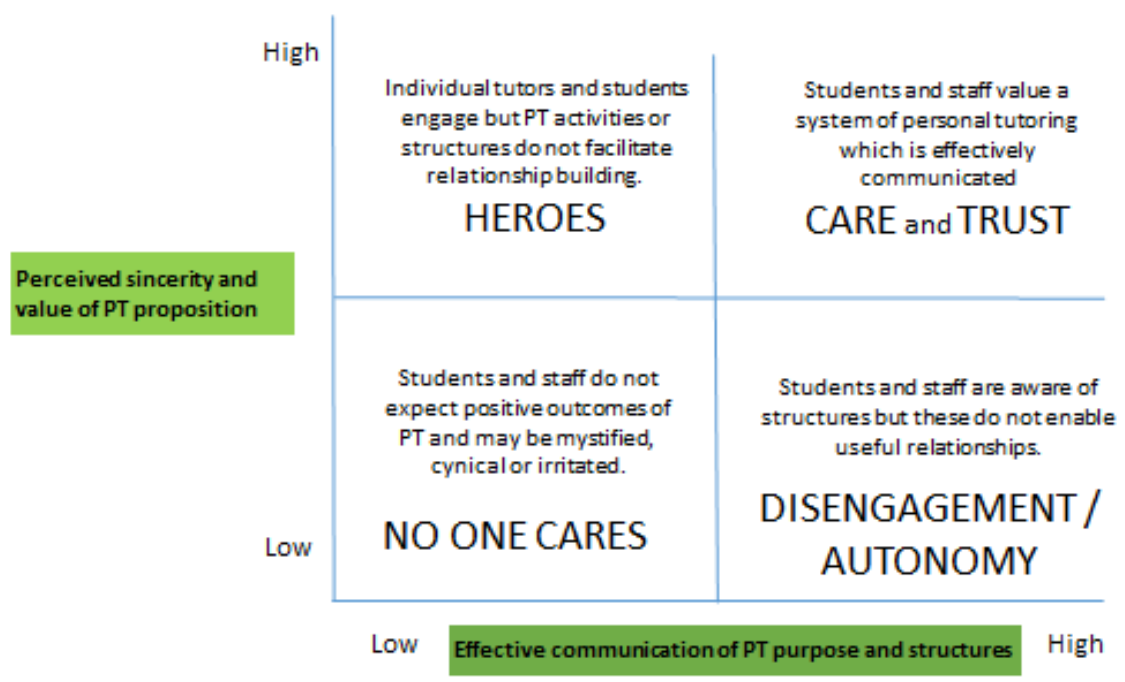

Figure 4. Two dimensional quadrant: design features of personalised support system and resulting experience.

In the upper right hand quadrant, positively perceived relationships of 'CARE' are most likely to result from a personalised support system that has a clearly communicated purpose, with clear structures that are designed and resourced to achieve that purpose, and where the students perceive this system to be sincerely offered by the institution and to have value to the student and their own perceived needs. Here students and staff are engaged in positive cycles of intent with the student at the centre. The students perceive a system they value, as it is designed to benefit them. Communication to students of a genuinely student-led and student-centred activity on a scale that suggests personalisation results in a successful system of personalised support.

In the lower left quadrant, the opposite is true. A lack of defined purpose, structures and effective communications of these, together with perceptions of an 'uncaring' and self-serving institution, combine to create a failing system of personalised support. Here there is a perception that NO ONE CARES. Students and staff do not expect positive outcomes of personal tutoring and may be mystified, cynical or irritated. 
The upper left and lower right quadrants characterise situations that are, perhaps quite common (Grey and Osborne, 2018; Ghenghesh 2018). In the upper left quadrant, purposes, structures and communications may be poor. This leaves individual students and staff to find each other and to agree a purpose and structure for a meaningful academic relationship. This may happen naturally depending on other factors such as class sizes, departmental accommodation and configuration of spaces and so on, but is largely left to happen, or not, by chance. There is no design intent. Thus 'heroic' tutors may emerge that students naturally are drawn towards, perhaps because of availability, approachability or other specific factors. Similarly, we might imagine 'heroic' students, who, despite the lack of designed opportunities to engage in meaningful relationships with academic staff, nonetheless may pursue this goal successfully.

The lower right quadrant is characterised by the existence of clearly communicated purposes and structures but without a perception of value either from those constructing the personalised support system (staff) or from students. Where the root of this perception of poor value emanates from staff utterances or behaviours (Ghenghesh, 2018), this may result in a lack of availability of staff to the students. Students may hear 'its not my job'; 'I'm too busy'; 'I can't do everything' and student perceptions may include 'staff think I am a nuisance'; or 'staff don't think students are worth their trouble'; or an understanding that a 'tick box' activity is being played out - all symptomatic of a perceived lack of sincerity. Either way, our evidence suggests that students quickly perceive low value and disengage. Arguably, this might lead to a kind of autonomy for students who seek out the resources they feel are lacking to satisfy their own perceived needs. Staff may feel frustrated by students' lack of engagement with what might seem to be a welldesigned and communicated system (Grey and Osborne, 2018; Ghenghesh, 2018; Sloan, Mann, Mellor and Jeffries, 2019). Staff may disengage, and feel puzzled or that they have wasted their time. Where staff are also pressurised from managers to achieve high satisfaction ratings, good attendance, progression and achievement data, this may lead to staff (and perhaps students) sensing an unresolvable conflict.

Where the perception of low value emanates from students it may be that students have not yet engaged with a tutor, or may have had a poor initial experience which quickly translates into an ongoing perception of poor value. This finding is also seen in Yale's 2019 study where students' first interaction in a personal tutoring setting is crucial to relationship formation.

In addition, mixed messages about autonomy and independence may happen in personalised support experiences in the lower right quadrant of Figure1. Yale, (2019a) explored the quality of personal tutoring relationships. One of her conclusions was that students can receive mixed 
messages about independence. In her study, younger students in particular were likely to perceive independence as a somewhat notional concept that they would work towards slowly. In this quadrant, students and staff may thus disengage because there is little perceived value - perhaps the first meeting was not well conceived, or was of low value to the student. It is therefore important to consider the value that a student will see in the offering of a first personal tutoring encounter and to tailor the offer accordingly.

\section{Implications for $\mathrm{HE}$}

This design tool provides some synthesised explanations to developers of personalised student support systems where students are not engaging well. Evaluations of existing systems, could consider the five elements represented in the tool to seek answers or to make improvements: purpose, structures, communications, perceived sincerity of the offer and perceived value to students. Given the importance of a meaningful academic relationship - how can we go about creating the conditions for these to flourish? A process of thinking about the purpose of personalised student support systems followed by the intentional design of activities and processes to achieve that purpose could usefully attend to the design considerations identified here.

Perhaps one of the principal causes of poor experience is the mismatch of the expectations of personalised care, with the resourcing of a supportive system within a mass higher education experience. An honest examination of the level of resourcing of a personalised student support system may yield uncomfortable truths, but also allow a more sincere offer to be made.

If resources allowed a tutor ten or fewer personal tutees in total across all cohorts, then a personalised experience for those ten students could be a reasonable expectation. However, where a tutor has ten student tutees at each of four levels of study, a personalised experience for all forty students becomes much less realistic. Institutions across the UK university sector have grappled with this problem, appointing senior tutors (Luck, 2010), running group tutorials (Stephen et al 2008) or instigating systems of peer mentoring to complement activity of academic and other staff are all responses to this situation (Stuart et al, 2019).

One further possibility is to be more explicit about the student's choice to engage or not with personal tutoring. Universities are under pressure to provide support structures for students that can anticipate and meet needs as they arise. However, choice to engage or not, is a freedom that students need to consider and negotiate for themselves if they are to become autonomous, critical operators that a UK university education intends. Reflection on the institutional wish to 'own' 
student attendance rather than to see this as a part of developing student autonomy and choice could also help to resolve some internal conflicts.

In this study, some students, particularly those who feel confident in their own resourcefulness, expressed a wish to engage with the system of care in accordance with their own judgement. A design decision can be made about whether (and how) this may be incorporated into the system. Students may wish to find both a sense of escape and a sense of belonging when they choose a university (Winter and Chapleo, 2017). The design of personalised support systems to synthesise these divergent but understandable motivations, needs careful consideration.

Previous work on students' experiences of personal tutoring in the UK accord with the findings of the present study especially in the desire for greater connectedness (Yale 2019; Tett et al 2017; Stephen et al 2008). Staff also express this desire - for example Stephen et al (2008) detail staff fear of inundation by student need (sometimes more perceived than actual), but also their strong desire to build better student teacher relationships via personal tutoring. This improved personal tutoring relationship does not always seem to happen within existing or revamped structures that are put in place for this purpose. Thus it seems likely that for many students the proposed value of personal tutoring activity is not perceived until they have actually experienced it. This is supported by recent research by Yale (2019), who has shown that the first interaction is vital. This could be because perceived value begins to accrue from this point forward.

There is a conundrum here that needs further exploration: of a university organisation that appears data driven and concentrates on the gathering and analysis of metrics, versus the emphasis placed on caring - a narrative that is stronger now than ever before (Tett et al, 2017).

Students value good connection with academic staff. Creating personalised student support systems that work for as many students as possible, will require flexible, purposeful and wellresourced activity. Further theory building (e.g. as suggested by Stuart et al, 2019) to achieve some measure of clarity, particularly in articulating the purpose of a personalised student support function still needs to be done.

\section{Conclusions}

Student perceptions of personal tutoring were analysed to create a design tool for student engagement with a system of personalised student support via tutoring. This work together with literature in the topic area indicates that five design considerations of a personalised student support system are: Purpose; Structures; Communications; Perceived sincerity of the support proposition; Perceived value (to students and staff).

Evaluation of a personalised student support system could use these five design considerations and additionally focus on the first meeting with the personal support/academic tutor. This meeting 
could be evaluated for efficacy in communicating a sense of value of personalised academic support to the student. This would be particularly important if students were explicitly allowed freedom to choose to engage or not, with the system.

Two further considerations are: a) congruence between the purpose(s) to be achieved and the amount of resource to be deployed b) how much freedom students will be given to engage or not with a system of personalised support, without judgement.

In relation to a) above, an activity such as personal tutoring is often given a high profile as part of the system of care for a student, but it may not always be allocated the resource that is required to allow fulfilment of expectations created for students, particularly around the idea of personalised care.

It may be difficult to convince all staff that the systems that are designed are ones in which all relevant tutors are invested. However, the activity of personalised student support can only happen systematically if there is some baseline of value that all tutors can agree. Further testing of these considerations may allow the development of these into principles for systematic design of personalised student support.

\section{References}

Attride-Stirling, J. (2001). Thematic networks: an analytic tool for qualitative research. Qualitative Research, 1(3), 385-405.

Barbé, T., Kimble, L. P., Bellury, L. M., \& Rubenstein, C. (2018). Predicting student attrition using social determinants: Implications for a diverse nursing workforce. Journal of Professional Nursing, 34(5), 352-356.

Braine, M. E., \& Parnell, J. (2011). Exploring student's perceptions and experience of personal tutors. Nurse education today, 31(8), 904-910.

Braun, V., \& Clarke, V. (2006). Using thematic analysis in psychology. Qualitative research in psychology, 3(2), 77-101.

Patrick, C., \& Miller, M. (2015). Academic advising within the academy. In Folsom. P., Yoder, F., \& Joslin., J. (Ed.), The new advisor guidebook: Mastering the art of advising (pp. 3953). San Francisco: Jossey-Bass.

Checkland, P. (1989). Soft systems methodology. Human systems management, 8 (4), 273-289.

Checkland, P., \& Poulter, J. (2006). Learning for action: a short definitive account of soft systems methodology and its use, for practitioners, teachers and students. Chichester: John Wiley and Sons Ltd. 
Crawford, N. L., \& Johns, S. (2018). An academic's role? Supporting student wellbeing in preuniversity enabling programs. Journal of University Teaching \& Learning Practice, 15(3), 2.

Earwaker, J. (1992). Helping and Supporting Students: Rethinking the Issues. London: Society for Research into Higher Education.

Ghenghesh, P. (2018). Personal tutoring from the perspectives of tutors and tutees. Journal of Further and Higher Education, 42(4), 570-584.

Grayson, A., Miller, H., \& Clarke, D. D. (1998). Identifying barriers to help-seeking: a qualitative analysis of students' preparedness to seek help from tutors. British Journal of Guidance and Counselling, 26(2), 237-253.

Gray, C. C., \& Perkins, D. (2019). Utilizing early engagement and machine learning to predict student outcomes. Computers \& Education, 131, 22-32.

Grey, D., \& Osborne, C. (2018). Perceptions and principles of personal tutoring. Journal of Further and Higher Education, https://doi.org/10.1080/0309877X.2018.1536258

Hagenauer, G., \& Volet, S. E. (2014). Teacher-student relationship at university: an important yet under-researched field. Oxford Review of Education, 40(3), 370-388.

Henri, D. C., Morrell, L. J., \& Scott, G. W. (2018). Student perceptions of their autonomy at University. Higher Education, 75(3), 507-516.

Kagan, C., \& Diamond, J. (2019). Marketisation, Teaching, Learning and the Student Experience. In University-Community Relations in the UK (pp. 77-100). Palgrave Macmillan, Cham.

Karpouza, E., \& Emvalotis, A. (2019). Exploring the teacher-student relationship in graduate education: a constructivist grounded theory. Teaching in higher education, 24(2), 121140.

Lochtie, D., McIntosh, E., Stork, A., \& Walker, B. (2018). Effective Personal Tutoring in Higher Education. Critical Publishing.

Luck, C., 2010. Challenges faced by tutors in higher education. Psychodynamic Practice, 16(3), pp.273-287.

Macfarlane, B. (2015). Student performativity in higher education: Converting learning as a private space into a public performance. Higher Education Research \& Development, 34(2), 338-350.

Mountford-Zimdars, A., Sanders, J., Moore, J., Sabri, D., Jones, S., \& Higham, L. (2017). What can universities do to support all their students to progress successfully throughout their 
time at university?. Perspectives: Policy and Practice in Higher Education, 21(2-3), 101110.

Roberts, J. (2018). Professional staff contributions to student retention and success in higher education. Journal of Higher Education Policy and Management, 40(2), 140-153.

Sloan, D., Manns, H., Mellor, A., \& Jeffries, M. (2019). Factors influencing student nonattendance at formal teaching sessions. Studies in Higher Education, 1-14.

Stephen, D. E., O'Connell, P., \& Hall, M. (2008). 'Going the extra mile', 'fire-fighting', or laissezfaire? Re-evaluating personal tutoring relationships within mass higher education. Teaching in Higher Education, 13(4), 449-460.

Stuart, K., Willocks, K., \& Browning, R. (2019). Questioning personal tutoring in higher education: an activity theoretical action research study. Educational Action Research, 120.

Tett, L., Cree, V. E., Mullins, E., \& Christie, H. (2017). Narratives of care amongst undergraduate students. Pastoral Care in Education, 35(3), 166-178.

Walsh, C., Larsen, C., \& Parry, D. (2009). Academic tutors at the frontline of student support in a cohort of students succeeding in higher education. Educational Studies, 35(4), 405-424.

Yale, A. T. (2019a). Quality matters: an in-depth exploration of the student-personal tutor relationship in higher education from the student perspective. Journal of Further and Higher Education, 1-14.

Yale, A. T. (2019b). The personal tutor-student relationship: student expectations and experiences of personal tutoring in higher education. Journal of Further and Higher Education, 43(4), 533-544.

Winter, E., \& Chapleo, C. (2017). An exploration of the effect of servicescape on student institution choice in UK universities. Journal of Further and Higher Education, 41(2), $187-200$. 